\title{
Development of a Mechanistic Model for Predicting Sliding Vapor Bubble Growth
}

\author{
Junsoo Yoo
}

August 2017

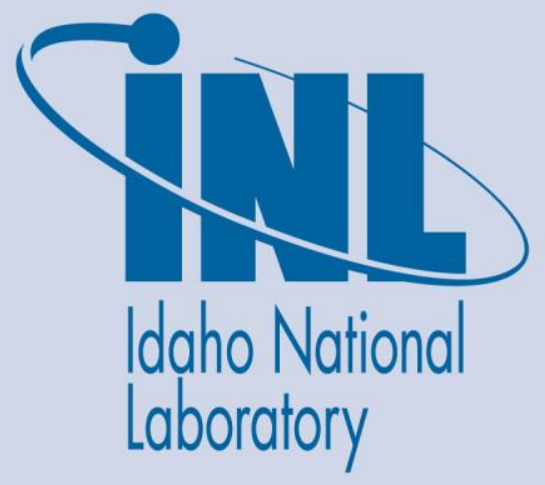

The INL is a U.S. Department of Energy National Laboratory operated by Battelle Energy Alliance 


\section{DISCLAIMER}

This information was prepared as an account of work sponsored by an agency of the U.S. Government. Neither the U.S. Government nor any agency thereof, nor any of their employees, makes any warranty, expressed or implied, or assumes any legal liability or responsibility for the accuracy, completeness, or usefulness, of any information, apparatus, product, or process disclosed, or represents that its use would not infringe privately owned rights. References herein to any specific commercial product, process, or service by trade name, trade mark, manufacturer, or otherwise, does not necessarily constitute or imply its endorsement, recommendation, or favoring by the U.S. Government or any agency thereof. The views and opinions of authors expressed herein do not necessarily state or reflect those of the U.S. Government or any agency thereof. 


\title{
Development of a Mechanistic Model for Predicting Sliding Vapor Bubble Growth
}

\author{
Junsoo Yoo
}

August 2017

Idaho National Laboratory Idaho Falls, Idaho 83415

http://www.inl.gov

Prepared for the

U.S. Department of Energy

Office of Nuclear Energy

Under DOE Idaho Operations Office

Contract DE-AC05-00OR22725 


\begin{abstract}
A new mechanistic model for predicting the growth of sliding vapor bubbles in subcooled boiling flows has been developed. This model employs a physical base that the same fundamental mechanisms applied to bubble growth at a nucleation site can also be applied to the growth of sliding bubbles. The heat transfer mechanisms considered are microlayer evaporation, evaporation of superheated liquid, and condensation. Modifications were made to the physical assumptions and reasoning applied to the existing growth models to reflect the intrinsic physics associated with the growth of sliding bubbles. The present model has been successfully validated against a broad set of subcooled flow boiling data, generated by three separate research groups using different working fluids and different heater surfaces. In particular, the model predictions well reproduced the physical dependencies of sliding bubble growth on the relevant flow boiling parameters (i.e., mass flux, wall superheat, and subcooling level) observed by the experiments.
\end{abstract}




\section{CONTENTS}

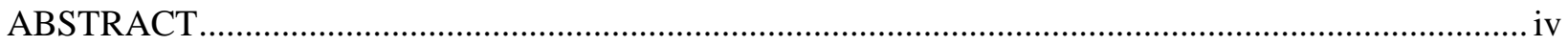

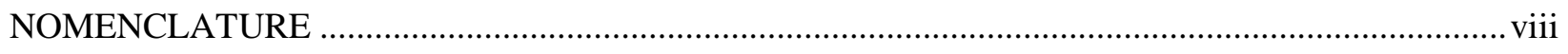

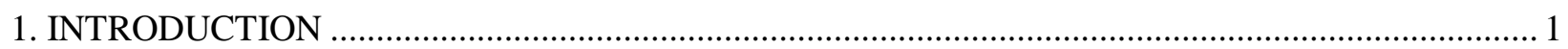

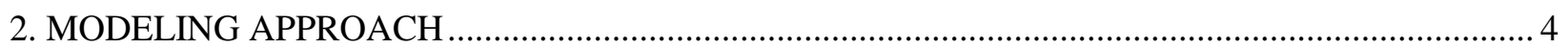

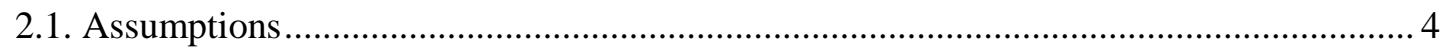

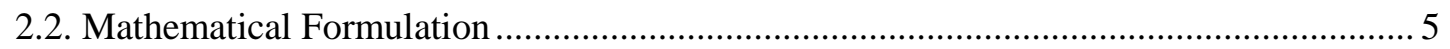

3. EXPERIMENTAL DATABASE FOR MODEL VALIDATION ...................................................... 8

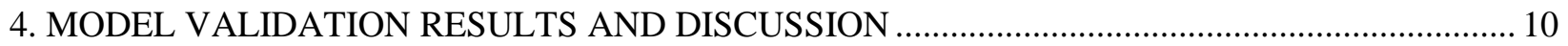

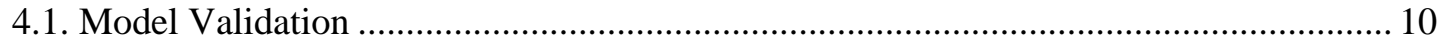

4.2. Contribution of Individual Heat Transfer Components ............................................... 11

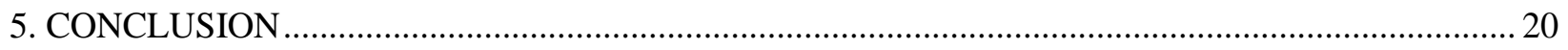

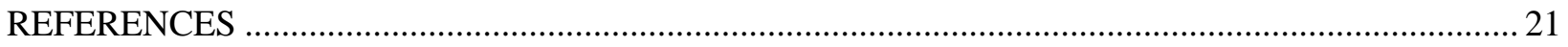




\section{FIGURES}

Fig. 1. Heat transfer mechanisms around a growing bubble in subcooled liquid. .................................... 2

Fig. 2. Heat transfer mechanism associated with the growth of sliding bubble....................................... 4

Fig. 3. Dependency of $A_{m l} / A_{t o t}$ on $J a$ and $\gamma$ for the growth of sliding bubbles. ..................................... 7

Fig. 4. Sliding bubble size prediction compared with Maity’s data $(2000,2001)$................................... 13

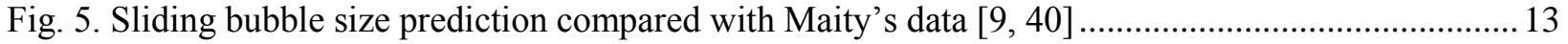

Fig. 6. Sliding bubble size prediction compared with Yoo et al.'s data [3] .............................................. 14

Fig. 7. Sliding bubble size prediction compared with Yoo et al.'s data [3] ........................................... 14

Fig. 8. Sliding bubble size prediction compared with Yoo et al.'s data [3] ........................................... 15

Fig. 9. Model prediction compared with Yoo et al.'s data [3] considering experimental

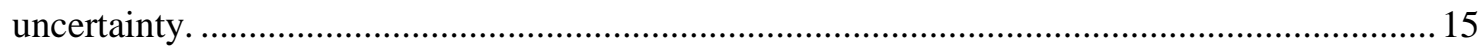

Fig. 10. Sliding bubble size prediction compared with Thorncroft et al.'s data [41] .............................. 16

Fig. 11. Sliding bubble size prediction compared with Thorncroft et al.'s data [41] ............................... 16

Fig. 12. Sliding bubble size prediction compared with Thorncroft et al.'s data [41] .............................. 17

Fig. 13. Contribution of individual heat transfer components estimated at two different wall superheat conditions of Yoo et al. experiment [3] ................................................................ 18

Fig. 14. Contribution of individual heat transfer components estimated at two different wall superheat conditions of Thorncroft et al. experiment [41]. 


\section{NOMENCLATURE}

\begin{tabular}{|c|c|c|c|}
\hline$b$ & bubble growth constant & $g$ & vapor \\
\hline$D$ & diameter $[\mathrm{m}]$ & $f$ & liquid \\
\hline$f$ & $\begin{array}{l}\text { portion of bubble surface in } \\
\text { contact with subcooled liquid }\end{array}$ & $m l$ & microlayer \\
\hline$\Gamma$ & & $s$ & solid \\
\hline$F_{b}$ & buoyancy force & sat & saturation \\
\hline$F_{d u}$ & $\begin{array}{l}\text { unsteady drag force due to } \\
\text { asymmetric bubble growth }\end{array}$ & $s l$ & sliding \\
\hline Fo & Fourier number & $s L L$ & $\begin{array}{l}\text { superheated liquid } \\
\text { layer }\end{array}$ \\
\hline$F_{s l}$ & shear lift force & sub & subcooling \\
\hline$F_{q s}$ & quasi-steady drag force & $w$ & wall \\
\hline$h_{c}$ & $\begin{array}{l}\text { condensation heat transfer } \\
\text { coefficient }\left[\mathrm{W} / \mathrm{m}^{2} / \mathrm{K}\right]\end{array}$ & & \\
\hline$h_{f g}$ & latent heat of vaporization $[\mathrm{J} / \mathrm{kg}]$ & Greeks & \\
\hline$J a$ & Jacob number & $\rho$ & density $\left[\mathrm{kg} / \mathrm{m}^{3}\right]$ \\
\hline$k$ & thermal conductivity $[\mathrm{W} / \mathrm{m} / \mathrm{K}]$ & $\eta$ & thermal diffusivity $\left[\mathrm{m}^{2} / \mathrm{s}\right]$ \\
\hline$N u$ & Nusselt number & $v$ & kinematic viscosity $\left[\mathrm{m}^{2} / \mathrm{s}\right]$ \\
\hline $\operatorname{Pr}$ & Prandtl number & $\delta_{t}$ & $\begin{array}{l}\text { thermal boundary- } \\
\text { laver thickness [m] }\end{array}$ \\
\hline$q$ & heat transfer rate $[\mathrm{W}]$ & & \\
\hline$q^{\prime \prime}$ & heat flux $\left[\mathrm{W} / \mathrm{m}^{2}\right]$ & & \\
\hline $\operatorname{Re}$ & Reynolds number & & \\
\hline$U$ & velocity $[\mathrm{m} / \mathrm{s}]$ & & \\
\hline$V$ & volume $\left[\mathrm{m}^{3}\right]$ & & \\
\hline \multicolumn{4}{|c|}{ Subscripts } \\
\hline 0 & initial & & \\
\hline$b$ & bubble & & \\
\hline$c$ & condensation & & \\
\hline$c l$ & contact line & & \\
\hline$e$ & effective & & \\
\hline$e v$ & evaporation & & \\
\hline
\end{tabular}




\section{Development of a Mechanistic Model for Predicting the Sliding Vapor Bubble Growth}

\section{INTRODUCTION}

Experimental evidences accumulated over the past several decades have clearly proven the significance of a sliding bubble's effect on wall heat transfer [1-4]. It has naturally promoted subsequent effort to reflect the influence of sliding bubbles in CFD boiling prediction [5, 6]. The main focus of CFD modeling is to introduce a heat transfer component for the sliding bubble to the original wall heat partitioning model so that the heat transfer effect can be better captured. In general, several key parameters are used to characterize the heat transfer induced by the sliding bubbles. These parameters include the bubble sliding distance, bubble growth during sliding, wall area influenced by sliding bubble, and sliding bubble velocity, etc., all of which are subject to modeling. However, the modeling of these socalled sliding bubble parameters still rely highly on assumptions, physical reasoning (without experimental evidence), and models or correlations originally developed for bubbles that grow at a nucleation site without sliding. In other words, the validity of each model or physical insight used to predict the sliding bubble parameters has little been demonstrated using experimental evidence. Additionally, as pointed out in a previous study [3,7], some of those assumptions and physical insights that have been employed in CFD boiling models are inconsistent with the experimental observation and, thus, need improvement.

Of the key sliding bubble parameters, the main focus of this study is bubble growth during sliding. In particular, we intend to develop a mechanistic model to predict the growth of sliding bubbles. A variety of models for predicting the bubble growth already exist in the literature, but most of them have originally been developed for the bubbles growing at a nucleation site. To the authors' knowledge, the only exception is the model proposed by Basu [8]. However, Basu's model is empirically correlated based on a part of Maity's data [9], and the model validation with other experimental data has not been found. To adequately predict the growth of a sliding bubble, a more mechanistic approach that reflects the underlying growth mechanism of sliding bubbles is required, as well as rigorous model validation.

With regard to vapor bubble growth, various models have been proposed while assuming the different mechanisms of evaporation around a bubble. Fig. 1 illustrates the possible heat transfer mechanisms during bubble growth on a heated wall. Depending on which evaporation mechanism is taken into account, the bubble growth models can be largely divided into four categories:

- Group 1: Growth models based on microlayer evaporation underneath a bubble [10-12]

- Group 2: Growth models based on the evaporation of superheated liquid [13-15]

- Group 3: Growth models based on the three-phase contact line evaporation [16]

- Group 4: Growth models based on the combined effect of two evaporation processes [17] (i.e., microlayer evaporation and relaxation microlayer evaporation). 


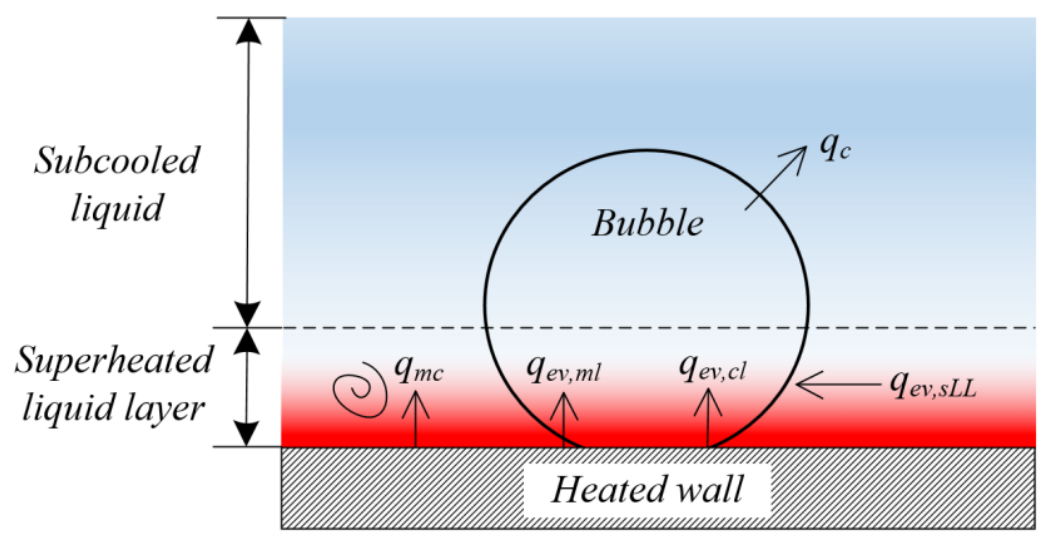

Fig. 1. Heat transfer mechanisms around a growing bubble in subcooled liquid.

Of these growth models, one of the most widely used in previous CFD boiling works is the Zuber model [13] (Group 2) originally proposed for a growing bubble in a uniformly superheated liquid. This model assumes that bubble growth is solely governed by transient heat conduction and does not explicitly consider the condensation heat transfer. Also, it was designed to eventually fit the experimental data using an empirical constant called "growth constant". However, there are no consistent criteria for determining the value of this growth constant. Many researchers who have assessed the Zuber model using their own experimental data have proposed different values or ranges for the growth constant [18-20]. There are other similar growth models that do not include the adjustable growth constant (e.g., Plesset and Zwick [15] and Scriven [21]), but the predictive performance is generally more limited.

To extend the application to subcooled boiling, there are other growth models that implement the two transfers of heat (i.e., evaporation and condensation) simultaneously. One of these models, proposed by Zuber [13], simply extended the existing growth model consisting of a single evaporation term by introducing a condensation term separately. Such extension was to depict bubble growth in a nonuniformly superheated liquid (e.g., growing and collapsing bubble in subcooled boiling conditions). Zuber [13] assumed that the magnitude of heat transfer due to condensation was equal to the heat transfer given from the wall (i.e., $q_{c}=q_{w}$ ). Later, Yun et al. [22] improved Zuber model by introducing the Ranz and Marshall correlation [23] to estimate the condensation heat transfer, as well as through several different applications of empirical constants. In a similar context, Unal [12] also proposed a heat balance equation considering both evaporation and condensation heat transfer. In the Unal model [12], evaporation was assumed to occur exclusively from the thin liquid film underneath a bubble called microlayer (Group 1). In addition, the condensation heat transfer coefficient $h_{c}$ was calculated by a method similar to Levenspiel [24]. The formulation of $h_{c}$ given by Unal [12] contained two empirical constants. This condensation model was later adopted by Hoang et al. [14]. Unlike Unal [12], however, Hoang et al. [14] considered the evaporation from the superheated liquid facing the lower bubble surface instead of the microlayer.

Recently, Colombo and Fairweather [25] attempted a more advanced form of growth model, taking into account both two different mechanisms of evaporation, i.e., microlayer evaporation and superheated liquid evaporation. Then, combining this with the contribution of condensation, they proposed a mechanistic formulation that can be applied to predict the bubble growth in subcooled flow boiling 
conditions. A similar approach was later taken by Raj et al. [26], but they evaluated the liquid temperature profile using the temperature wall function for a single-phase turbulent flow [27] to determine the portion of a bubble in contact with the subcooled liquid.

As noted before, although various types of growth models exist in the literature, most of them are for predicting bubble growth at a nucleation site. These models, however, are not generally applicable for predicting the growth of a sliding bubble after leaving the nucleation site. The fundamental heat transfer mechanisms are not expected to be very different, but the research should include different physical assumptions and physical reasoning to correctly deal with the growth of sliding bubbles. For instance, since the microlayer diminishes while the bubble grows at a nucleation site before sliding, the ratio between the microlayer and total bubble surface area (i.e., $A_{m l} / A_{t o t}$ ) used in the existing growth models [10, $25,26]$ should become smaller for the sliding bubble. This means that the relative contributions of individual heat transfer mechanisms to the overall bubble growth can also be different depending on the bubble growth stage such as nucleating or sliding. From the modeling perspective, another noteworthy issue is the condensation model. The correlation of Ranz and Marshall [23], often employed in the existing growth models $[22,25,28]$, tends to significantly overestimate the amount of condensation heat transfer when applied to predict the bubble growth at a nucleation site. We have found the same issue while predicting the growth of sliding bubbles with the Ranz and Marshall correlation. The condensation model of Unal [12] has the same problem. It is important to note that the longer the prediction time for the bubble growth, the more obvious the issue of these condensation models becomes. Aside from these, careful attention must also be paid to various parameters such as thermal boundary-layer thickness, heater wall properties, and growth constant, to adequately model the growth of sliding bubbles.

The objective of this work is to develop a generalized mechanistic model to predict the growth of sliding bubbles. The present model considers the major heat transfer mechanisms that have been experimentally identified for bubbles growing in saturated and subcooled boiling conditions [29, 30] (i.e., (i) evaporation of microlayer, (ii) evaporation of superheated liquid, and (iii) condensation). In addition, modifications are made to the physical assumptions and reasoning as well as the empirical constant applied to the existing growth models to reflect the intrinsic physics associated with the sliding bubble growth. The present model is then validated with a broad set of subcooled flow boiling data that have been generated by separate research groups.

Note that the growth of sliding bubble can have significant impact on the evaluation of other sliding bubble parameters, such as the area of influence of the sliding bubble [7], bubble sliding velocity [3], and thus, the overall wall heat transfer characteristics induced by sliding bubbles $[3,7,31]$. Also, the accurate prediction of bubble growth during sliding is critical for the predictive performance of the force balance model [32], especially in terms of predicting the bubble lift-off diameter. This is because the sliding bubble size and sliding bubble growth rate are essential to evaluate the various force components (e.g., $F_{b}$, $F_{q s}, F_{d u}$, and $\left.F_{s l}\right)$. All of these indicate the significance of the present work. 


\section{MODELING APPROACH}

\subsection{Assumptions}

To model the growth of sliding vapor bubble in subcooled boiling flow, the present model has been established with the following assumptions:

(i) Due to the stochastic feature of sliding bubble growth [31], a statistical approach is taken. This means that all the predictions made by the present model (i.e., bubble diameter and growth rate during sliding) represent the values of ensemble average. Therefore, the discrepancies between the model prediction and the experiment do not necessarily indicate model limitation unless the experimental data are represented by the reliable statistics using a sufficient number of samples.

(ii) Growth of sliding bubbles occurs due to the evaporation of both the microlayer $\left(q_{e v, m l}^{\prime \prime}\right)$ and the superheated liquid layer $\left(q_{e v, s L L}^{\prime \prime}\right)$. The heat transfer process is approximated by transient heat conduction.

(iii) Condensation only occurs on the top half of the sliding bubble surface (i.e., $f=0.5$ ).

(iv) Bubble shape is kept spherical during sliding.

(v) Sliding bubble growth is solely governed by the heat transfer process, neglecting the effect of inertia.

(vi) The microlayer underneath a sliding bubble has no thermal capacity and an infinite conductivity (i.e., the temperature of the heated wall at the bubble base, initially at $T_{w}$, would shortly reach $T_{\text {sat }}$ as soon as the microlayer is formed).

(vii) The area of microlayer relative to the area of the entire bubble surface (i.e., $\left.A_{m} / A_{t o t}\right)$ during bubble sliding depends on the wall superheat and thermal properties of the heater wall (see Section 2 for details).

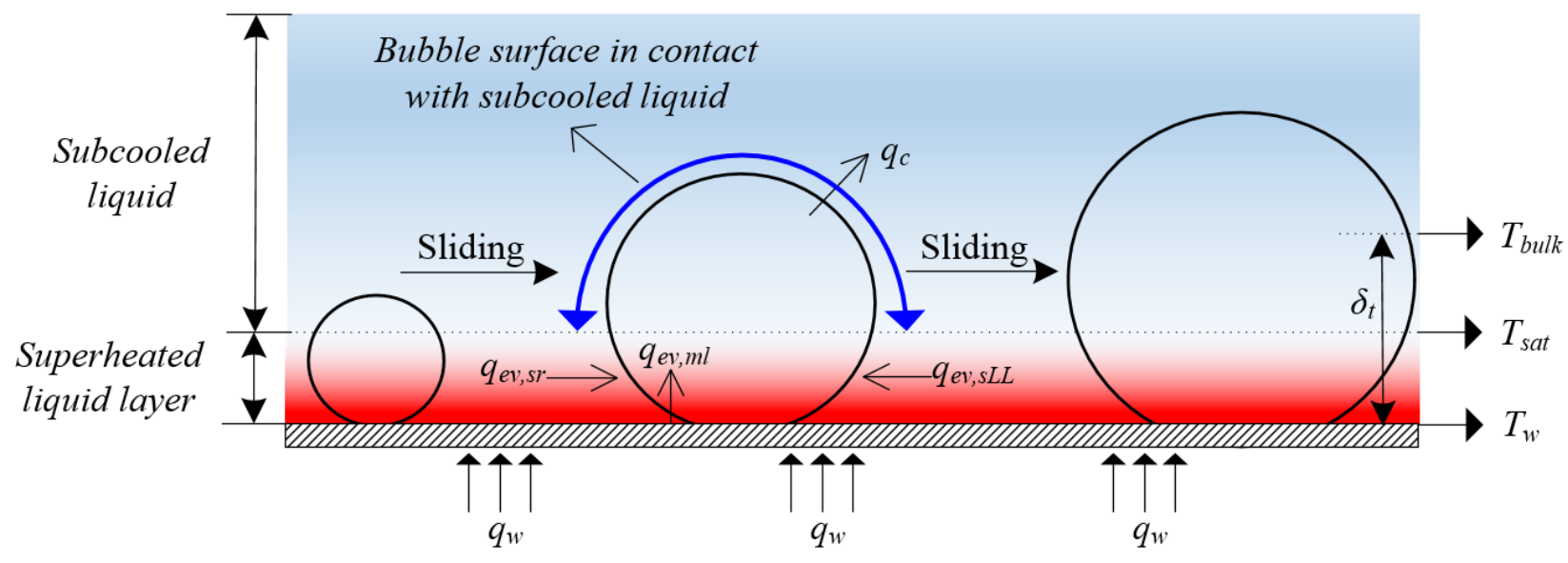

Fig. 2. Heat transfer mechanism associated with the growth of sliding bubble. 


\subsection{Mathematical Formulation}

The present model incorporates the two different mechanisms of evaporation, i.e., microlayer evaporation $\left(q_{e v, m l}^{\prime \prime}\right)$ and evaporation within the superheated liquid layer $\left(q_{e v, s L L}^{\prime \prime}\right)$. Also, condensation heat transfer $\left(q_{c}^{\prime \prime}\right)$ is combined to apply the present model to the growth of sliding bubbles in subcooled liquids. As a consequence, the overall energy balance equation can be expressed as

$$
\rho_{g} h_{f g} \frac{d V_{b}}{d t_{s l}}=\gamma q_{e v, m l}^{\prime \prime} A_{m l}+(1-f) q_{e v, r m}^{\prime \prime} A_{t o t}-f q_{c}^{\prime \prime} A_{t o t}
$$

(where $V_{b}$ is the entire volume of the bubble $\left(=\pi D^{3} / 6\right), t_{s l}$ is bubble sliding time, $A_{t o t}$ is the total area of the bubble surface $\left(=\pi D^{2}\right), A_{m l}$ is the area of microlayer underneath the bubble, $f$ is the portion of bubble surface in contact with subcooled liquid, and $\gamma$ is a constant to account for the thermal properties of the heater wall as described by Unal [12] $\left.\left(\gamma=\sqrt{\frac{k_{s} \rho_{s} c_{s}}{k_{f} \rho_{f} c_{p, f}}}\right)\right)$

The heat flux components (i.e., $q_{e v, m l}^{\prime \prime}, q_{e v, r m}^{\prime \prime}$, and $q_{c}^{\prime \prime}$ ) used in Eq. (1) are detailed as follows:

(i) Microlayer evaporation

$$
q_{e v, m l}^{\prime \prime}=\gamma \operatorname{Pr}^{-0.5}\left(\rho_{f} c_{p, f} \Delta T_{w}\right) \eta_{f}^{0.5} t_{s l}^{-0.5}
$$

The model of Cooper and Lloyd [10] is taken to mimic microlayer evaporation. The present model, however, introduced an additional constant $\gamma$ to the original model to account for the effect of the thermal properties of the heater wall as proposed by Unal [12].

(ii) Superheated liquid layer evaporation:

$$
q_{e v, s L L}^{\prime \prime}=\frac{b k_{f} \Delta T_{w}}{\sqrt{\pi \eta_{f} t_{s l}}}\left(\text { where } \Delta T_{w}=T_{w}-T_{s a t}\right)
$$

Zuber's model [13] is taken to depict the heat transfer contribution through the superheated liquid layer. The model constant $b$, the so-called growth constant, is usually determined empirically; a variety of values that depend on the experimental conditions and working fluids $[13,18,19,33]$ as well as the growth stage of the bubble [20], have been suggested by previous researchers. However, it was found that the growth constant $b$ for sliding bubble can be fixed irrespective of subcooled flow boiling conditions or working fluids once all the relevant heat transfer mechanisms are properly reflected. The growth constant $b$ is fixed at 0.24 in the present model.

(iii) Condensation:

$$
q_{c}^{\prime \prime}=h_{c} \Delta T_{s u b}
$$

The modeling of the condensation heat transfer coefficient $h_{c}$ is based on a method similar to Unal [12] and Lavenspiel [24], which is expressed as 


$$
h_{c}=\frac{C h_{f g} D}{2\left(1 / \rho_{g}-1 / \rho_{f}\right)}
$$

(where $C$ is the empirical constant and $D$ is bubble diameter)

However, in Eq. (5) the empirical constant taken by Unal [12], which is dependent on pressure and liquid bulk velocity, causes significant overestimation of the condensation heat transfer in the present application (i.e., bubble sliding). This issue is hard to avoid even if another condensation model is applied (i.e., the Ranz and Marshall correlation) [23]. The problem of the Ranz and Marshall correlation [23] of over-estimating the condensation rate has also been reported by Marco and Fairweather [25] and Sugrue and Buongiorno [28]. One thing to note is that the limitation of above-mentioned condensation models becomes more problematic as the bubble growth time increases. This problem was relatively unclear in the previous studies because most of the previous works focused on the initial phase of bubble growth during a very short time $(<1 \sim 10 \mathrm{~ms})$. In addition, while there are other possible experimental correlations [34-37] for bubble condensation, they have been developed mainly for free-rising bubbles in subcooled liquid, not for the bubbles growing while attached to the heated wall as in present application.

Therefore, to properly address the problem of the condensation model, we have selected a different value for the empirical constant than used in the Unal model [12], i.e., $C=0.1$ [1/(K·s)] in Eq. (5). The suitability of using this value will be justified through the model validation process described below in Section 5.

Incorporating Eqs. (2)-(5) into Eq. (1) and simplifying, Eq. (1) reduces to

$$
\frac{d D\left(t_{s l}\right)}{d t_{s l}}=2 \gamma \operatorname{Pr}^{-0.5} J a \cdot \eta_{f}^{0.5} t_{s l}^{-0.5}\left(\frac{A_{m l}}{A_{t o t}}\right)+(1-f) \frac{2 b k_{l}\left(T_{w}-T_{s a t}\right)}{\rho_{g} h_{f g} \sqrt{\pi \eta_{f}}} t_{s l}^{-0.5}-f \frac{2 h_{c} \Delta T_{s u b}}{\rho_{g} h_{f g}}
$$

Concerning the area ratio $A_{m l} / A_{t o t}=1 / C_{l}$ in Eq. (6), Cooper and Lloyd [10] adopted $C_{l}$ between 0.8 and 1.2 while Colombo and Fairweather optimized them later to $C_{l}=1.78$. However, these values are determined for the bubbles growing at a nucleation site and hence, $C_{1}$ should be further optimized to deal with the sliding bubble for the present application. In general, the $A_{m l} / A_{t o t}$ is expected to be significantly reduced for the sliding bubble because the microlayer will diminish progressively as the bubble grows at the nucleation site before entering into sliding phase [38, 39]. In addition, in the case of sliding bubble, the present model assumes that the value of $A_{m l} / A_{\text {tot }}$ used in Eq. (6) depends on the degree of wall superheat (i.e., $\Delta T_{w}$ ) as well as heater wall thermal properties. Lastly, $\gamma$ is introduced to the first term on the RHS of Eq. (6) to consider that the contribution of microlayer evaporation to the growth of sliding bubble depends on the thermal properties of the heater wall, as claimed by Unal [12]. This means that a large value of $\gamma$ will make the microlayer evaporate more readily, which in turn will lead to a large contribution of microlayer evaporation to the overall growth of the sliding bubble. On the other hand, the area fraction of microlayer $A_{m l} / A_{t o t}$ during the bubble sliding will decrease as $\gamma$ or $\Delta T_{w}$ increases because in these conditions the larger portion of the microlayer is expected to be consumed before the bubble leaves the nucleation site through sliding. Fig. 4 clearly shows this relation between $A_{m l} / A_{\text {tot }}$ and $\gamma$ or $J a$, which was obtained while comparing the present model predictions with the sliding bubble growth data (Section 3 ). Based on this observation, the present model calculates the value of $A_{m l} l A_{t o t}$ for the sliding bubble as follows: 


$$
\frac{A_{m l}}{A_{t o t}}=1.22 \gamma^{-0.79} \exp (-0.204 \cdot J a)
$$

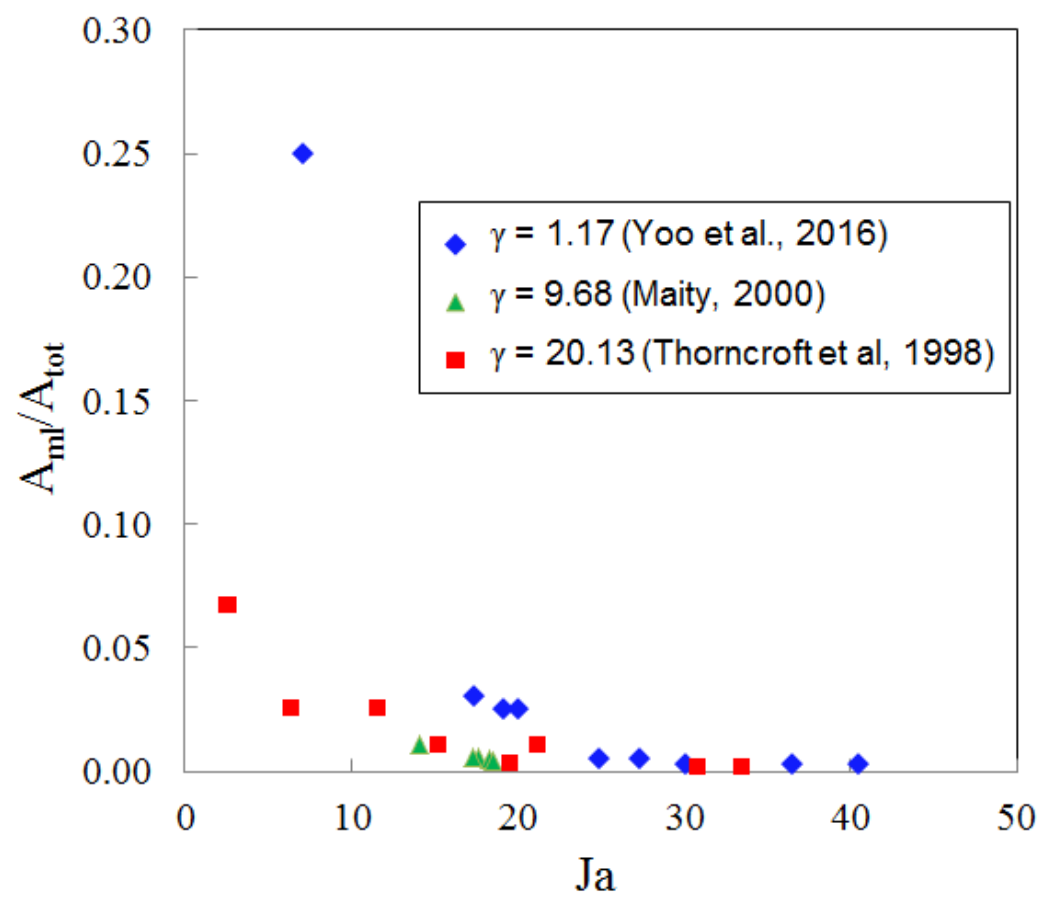

Fig. 3. Dependency of $A_{m l} / A_{t o t}$ on $J a$ and $\gamma$ for the growth of sliding bubbles. 


\section{EXPERIMENTAL DATABASE FOR MODEL VALIDATION}

To evaluate the validity of the present model across a wide range of subcooled flow boiling conditions, experimental data depicting the growth of sliding bubble have been collected. Table 1 summarizes the information on the experiments and the number of test cases (or experimental conditions) for each experiment used for the present validation. A total of three datasets ( 23 test cases included) generated by separate research groups have been collected, each of which used different working fluid (i.e., water (Maity [9, 40]), NOVEC ${ }^{\mathrm{TM}} 7000$ (Yoo et al. [3]), and FC-87 (Thorncroft et al. [41])). All the bubble growth data were taken for the bubbles sliding through a vertical upward flow channel at atmospheric pressure. Table 2 summarizes the specific experimental conditions used for the present model validation. The last column of Table $2, D_{0}$, denotes the bubble departure diameter or the initial sliding bubble diameter measured at each experiment. In Yoo et al. [3], the mean growth curves for sliding bubbles are given with respect to the bubble location during sliding along the flow path, instead of the bubble sliding time $\left(t_{s l}\right)$. Therefore, the sliding bubble growth data over time, $d D\left(t_{s l}\right) / d t$, was obtained by re-estimation using the equation $\frac{d D\left(t_{s l}\right)}{d t}=\frac{d D\left(t_{s l}\right)}{d x} \cdot \frac{d x}{d t_{s l}}=\frac{d D\left(t_{s l}\right)}{d x} \cdot u_{b}$ (where $x$ is the bubble location during sliding along the flow path and $u_{b}$ is the bubble sliding velocity, both of which were measured by Yoo et al. [3]). It is also noted that the model validation with Yoo et al.'s data [3] has been performed using the average wall temperature measured over the bubble sliding distance and within the area of bubble influence; the specific values of $\Delta T_{w}$ based on this are given in Table 2. Other key assumptions and evaluation methods used to estimate the values that are not directly available from the original papers are described in the footnotes below in Tables 1 and 2.

Table 1. Experimental databases for the validation of the present model.

\begin{tabular}{|c|c|c|c|c|c|c|}
\hline \multirow{2}{*}{ Authors } & \multirow{2}{*}{$\begin{array}{l}\text { Working } \\
\text { Fluid }\end{array}$} & \multirow{2}{*}{$\begin{array}{l}\text { Total Number of } \\
\text { Test Cases Used for } \\
\text { Model Validation }\end{array}$} & \multicolumn{4}{|c|}{ Test Conditions } \\
\hline & & & $R e^{*}$ & $B o^{*}\left(\times 10^{-4}\right)$ & $J a^{*}$ & $N_{\text {sub }}{ }^{*}$ \\
\hline $\begin{array}{c}\text { Thorncroft et al. } \\
\text { [41] }\end{array}$ & FC-87 & 9 & $\begin{array}{c}5,300- \\
8,900\end{array}$ & $3.68-13.7$ & $2.63-33.6$ & $9.49-15.8$ \\
\hline Maity $[9,40]$ & Water & 5 & $\begin{array}{l}9,500- \\
17,000\end{array}$ & $\begin{array}{c}0.184- \\
0.492\end{array}$ & $14.1-18.6$ & $\begin{array}{c}0.898- \\
13.5\end{array}$ \\
\hline Yoo et al. [3] & $\begin{array}{c}\text { NOVEC- } \\
7000\end{array}$ & 9 & $\begin{array}{l}6,300- \\
15,600\end{array}$ & $2.05-3.97$ & $7.15-40.5^{\dagger}$ & $10.8-25.0$ \\
\hline
\end{tabular}

${ }^{\dagger}$ Jacob numbers were estimated using the average wall temperature over the sliding distance within the area of bubble influence. 
$* \operatorname{Re}=\frac{U_{f} L}{v_{f}}, B o=\frac{q_{w}^{\prime \prime}}{G h_{f g}}, J a=\frac{\rho_{f} c_{p, f}\left(T_{w}-T_{s a t}\right)}{\rho_{g} h_{f g}}, N_{s u b}=\frac{\Delta h_{s u b, i n} \Delta \rho}{h_{f g} \rho_{g}} \quad$ (U $U_{f}$ is liquid bulk velocity, $L$ is channel equivalent diameter, $\Delta h_{\text {sub,in }}$ is inlet liquid subcooling enthalpy, and $\Delta \rho$ is density difference between liquid and vapor.)

Table 2. Experimental conditions used for the validation of the present model.

\begin{tabular}{|c|c|c|c|c|c|c|c|}
\hline \multirow[b]{2}{*}{ Authors } & \multirow{2}{*}{$\begin{array}{l}\text { Working } \\
\text { Fluid }\end{array}$} & \multicolumn{6}{|c|}{ Test Conditions } \\
\hline & & $\gamma^{*}$ & $G\left[\mathrm{~kg} / \mathrm{m}^{2} \mathrm{~s}\right]$ & $\begin{array}{c}q_{w}^{\prime \prime} \\
{\left[\mathrm{kW} / \mathrm{m}^{2}\right]}\end{array}$ & $\Delta T_{w}\left[{ }^{\circ} \mathrm{C}\right]$ & $\Delta T_{\text {sub,in }}\left[{ }^{\circ} \mathrm{C}\right]$ & $D_{0}[\mathrm{~mm}]^{(1)}$ \\
\hline \multirow{9}{*}{$\begin{array}{l}\text { Thorncroft et } \\
\text { al. (1998) }\end{array}$} & \multirow{9}{*}{ FC-87 } & \multirow{9}{*}{20.13} & 195.1 & 2.83 & 0.54 & 2.98 & 0.094 \\
\hline & & & 192 & 4.80 & 2.39 & 2.83 & 0.165 \\
\hline & & & 194 & 7.36 & 4.38 & 2.86 & 0.207 \\
\hline & & & 244 & 3.52 & 0.55 & 3.06 & 0.105 \\
\hline & & & 258 & 6.92 & 3.15 & 3.27 & 0.147 \\
\hline & & & 255 & 10.9 & 6.34 & 2.78 & 0.199 \\
\hline & & & 315 & 3.63 & 1.32 & 2.52 & 0.112 \\
\hline & & & 319 & 7.26 & 4.04 & 2.29 & 0.16 \\
\hline & & & 315 & 11.8 & 6.89 & 1.96 & 0.204 \\
\hline \multirow{5}{*}{$\begin{array}{c}\text { Matity et al. } \\
(2000 \\
2001)^{(2)}\end{array}$} & \multirow{5}{*}{ Water } & \multirow{5}{*}{9.68} & 239.6 & 9.93 & 5.9 & 0.3 & 1.2 \\
\hline & & & 239.6 & 18.85 & 6.1 & 2.5 & 0.7 \\
\hline & & & 239.6 & 26.59 & 6.2 & 4.5 & 0.6 \\
\hline & & & 134.2 & 6.30 & 4.7 & 0.8 & 1.2 \\
\hline & & & 134.2 & 10.23 & 5.8 & 0.8 & 1.4 \\
\hline \multirow{9}{*}{$\begin{array}{l}\text { Yoo et al. } \\
(2016)^{(3)}\end{array}$} & \multirow{9}{*}{$\begin{array}{c}\text { NOVEC- } \\
7000\end{array}$} & \multirow{9}{*}{1.17} & 280 & 11.9 & 9.36 & 13.5 & 0.307 \\
\hline & & & 420 & 12.2 & 3.59 & 13.5 & 0.078 \\
\hline & & & 420 & 20.4 & 15.26 & 13.5 & 0.206 \\
\hline & & & 420 & 23.7 & 18.52 & 13.5 & 0.229 \\
\hline & & & 420 & 17.1 & 10.25 & 13.5 & 0.188 \\
\hline & & & 560 & 24.0 & 13.26 & 13.5 & 0.181 \\
\hline & & & 700 & 24.2 & 9.87 & 13.5 & 0.116 \\
\hline & & & 700 & 30.9 & 14.47 & 13.5 & 0.122 \\
\hline & & & 420 & 20.1 & 19.9 & 4.5 & 0.298 \\
\hline
\end{tabular}

$\gamma$ was calculated based on the heater surface properties of each experiment (Nichrome, Silicon, and Polyimide film was used by Thorncroft et al. [41], Maity [9, 40], and Yoo et al. [3, 31], respectively.).

${ }^{(1)}$ This is bubble departure diameter or initial sliding bubble diameter.

${ }^{(2)}$ Heat flux values were estimated using Eq. (3) in Unal's paper [12].

(3) $\Delta T_{w}$ was obtained based on the average wall temperature measured over the bubble sliding distance and within the wall area of bubble influence. Note that these values are inconsistent with those of $J a$ given in Yoo et al. [3] (Table 2) because they were calculated based on the local wall temperature measured at the elevation of the nucleation site. 


\section{MODEL VALIDATION RESULTS AND DISCUSSION}

Model validation is one of the most important parts of the present work. Once the mathematical form of the model is formulated (i.e., Eq. (6)), the predictive performance must be evaluated in terms of whether it can reproduce the physical effects that have been observed by experiments. The more data we have in various experimental conditions, the better for model validation. If any physical assumptions used in the present model (Section 2) ignore and/or distort the relevant physics associated with the growth of a sliding bubble, model prediction may show significant deviations from the experimental observations. That is, model validation is the ultimate process to demonstrate the suitability of the present model. In this section, the predictions made by the present model are compared with the sliding bubble growth datasets described in Section3. As noted before, the data have been generated in various subcooled flow boiling conditions by three separate research groups using different working fluids (i.e., water, NOVEC-7000, and FC-87) on different heater walls. A main objective is to determine whether the present model is consistently able to reproduce the physical dependency of the sliding bubble growth on relevant flow boiling parameters (e.g., subcooling level, mass flux, and wall superheat) observed by the experiments.

\subsection{Model Validation}

Figs. 4 and 5 show comparisons of model predictions with the experimental data of Maity [9] and Maity and Dhir [40] using water as working fluid. Fig. 4 compares three sets of experimental data measured at different levels of subcooling for a given mass flux, while Fig. 5 compares two other data sets measured at different wall superheat conditions. Overall, the model predicts the experimental data fairly well. Note that the sliding bubble growth data shown in Figs. 4 and 5 include three measurements that Maity [9] performed repeatedly in each test case.

Another validation work, shown in Figs. 6-8, was performed against the data sets generated by Yoo et al. [3] using different working fluid NOVEC-7000. Fig. 6 shows that the mean growth of sliding bubble measured at two different mass fluxes are well predicted by the present model. Although some discrepancies are found, they are well within the range of experimental uncertainty. Fig. 7 shows that the model can also well reproduce the physical dependency of sliding bubble growth on wall heat flux observed in Yoo et al.'s experiment [3]. A similar sensitivity test on wall heat flux $\left(q_{w}{ }^{\prime}\right)$ is shown in Fig. 8 at a higher mass flux condition $\left(\mathrm{G}=700 \mathrm{~kg} / \mathrm{m}^{2} \mathrm{~s}\right)$. In this case, however, the discrepancy between the model predictions and experimental measurement was relatively large, especially in the early phase of bubble sliding when $q_{w}{ }^{\prime \prime}=24.2 \mathrm{~kW} / \mathrm{m}^{2}$ (test case of lower $q_{w}{ }^{\prime}$ ). Aside from the potential limitation of the present model, this discrepancy is partially attributed to the difficulty of experimental measurement (i.e., bubble size measurement). In Yoo et al.'s experiment [3], the quality of bubble images was relatively poor when images were taken at high mass flux conditions (i.e., $G=700 \mathrm{~kg} / \mathrm{m}^{2}$ s), which in turn made it difficult to achieve precise analysis of bubble images. This is especially true for the small size of sliding bubbles positioned at and near the nucleation site. Therefore, this experimental limitation is responsible for the discrepancy shown in Fig. 8. To better understand the level of discrepancy, the present model prediction is compared in Fig. 9 with Yoo et al.'s data while taking the experimental uncertainty into account. For this comparison, we selected two test cases having resulted in the largest discrepancy between the model and Yoo et al.'s experiment. Fig. 9 shows that the model predictions are still within the range of experimental uncertainty. This leads to the conclusion that the present model is successful in 
predicting the growth of sliding bubbles and its physical dependency on various flow boiling parameters observed by Yoo et al. [3].

Following the validation against both Maity [9, 40] and Yoo et al.'s [3] experiments, the present model was also compared with the subcooled flow boiling data of Thorncroft et al. [41] in which another type of working fluid, FC-87, was employed. The results are shown in Figs. 10-12. Overall, the present model agrees well with the growth data taken by Thorncroft et al [41], but in some cases, noticeable discrepancies are found. In particular, those discrepancies are often found at the test cases of relatively higher wall superheat $\left(\Delta T_{w}\right)$. As for these discrepancies, there are a couple of possible issues for the experiment and the modeling assumption. First, according to Thorncroft et al. [41], the bubbles emanating from the neighboring nucleation sites and/or from the same nucleation site were observed to collide and coalesce at higher heat flux $\left(q_{w}\right.$ ") conditions (thus, higher $\left.\Delta T_{w}\right)$. This may cause the growth curve of the experiments to be steeper than the model predictions because the present model does not account for such bubble dynamics during sliding. In fact, the present model provides better performance when predicting the growth data taken under experimental conditions in which bubble collisions and coalescence were not observed (i.e., at low $q_{w}$ " or at low $\Delta T_{w}$, as shown in Figs. 10-12). Second, Thorncroft et al. [41] argued that the bubble collisions and coalescence limited the amount of available growth data used to create the mean growth curve. This means that the sample number was not enough to achieve the reliable statistics (i.e., mean). As discussed intensively in our previous work [42], this can also be a significant source of uncertainty or statistical error that the experimental data may have. The last issue is related to the assumption that the present model takes, that the upper half of the bubble is in contact with subcooled liquid during sliding (i.e., $f=0.5$ ). This oversimplifies the physics and thus can be the other source of model prediction error. The present model tends to show more limitation when applied to predict the sliding bubble growth data measured at high wall superheat $\left(\Delta T_{w}\right)$ and/or low mass flux $(G)$ conditions. This is because in these conditions the liquid thermal boundary layer becomes thicker and develops more slowly along the sliding path [3], making the model assumption $f=0.5$ farther away from the actual physics (see Section 5 for more discussion on the model limitation).

Given the discussion above for the uncertainties of experimental data, it can be concluded that although some discrepancies are found, the present model predicts the sliding bubble growth data, which have been generated by three different research groups, with satisfactory accuracy.

\subsection{Contribution of Individual Heat Transfer Components}

One important feature of the present model is that the contribution of microlayer evaporation to the overall growth of sliding bubbles depends on both heater wall properties and wall superheat $\Delta T_{w}$ as shown in Eq. (7). This is to account for the fact that the microlayer is depleted while evaporating before the bubble slides away from the nucleation site (Section 2.2). As a result, in the present model the relative contributions of each heat transfer component to the overall bubble growth are highly dependent on the operating conditions of the flow boiling system.

Fig. 13 compares the two test cases of the Yoo et al. experiment with the present model; the lower $\Delta T_{w}$ case is shown on the top and the higher $\Delta T_{w}$ case is shown on the bottom. In Fig. 13, the contributions due to microlayer evaporation, superheated liquid layer evaporation, and condensation are shown separately. Note that the condensation part is exhibited as absolute values for the convenience of understanding. For the lower $\Delta T_{w}$ case (Fig. 13, top), the microlayer evaporation contributes most to the 
overall growth of sliding bubble. However, when $\Delta T_{w}$ is higher (Fig. 13, bottom), the contribution of superheated liquid evaporation becomes much greater than the contribution of microlayer evaporation. This is because the present model assumes that the microlayer is depleted more readily at a higher $\Delta T_{w}$ before the bubble slides away from the nucleation site, resulting in the smaller value of $A_{m} / A_{t o t}$ in Eq. (6). Fig. 14 compares the present model and the sliding bubble growth data of Thorncroft et al. in a similar way to Fig. 13. Fig. 14 also shows that the contribution of the microlayer to the overall growth of sliding bubbles is significantly reduced at the test case of higher $\Delta T_{w}$ shown on the bottom. It is noted that the thermal properties of the heater wall (i.e., nichrome) employed by Thorncroft et al. [41] may cause such variation to become more dramatic due to the large value of $\gamma$ (See Fig. 3 and Table 2). Also, the results shown in Figs. 13 and 14 are in contrast to the existing bubble growth models [25, 26] which always predict a significant contribution of microlayer evaporation. In both Figs 13 and 14, the effect of condensation is found to be relatively small. 


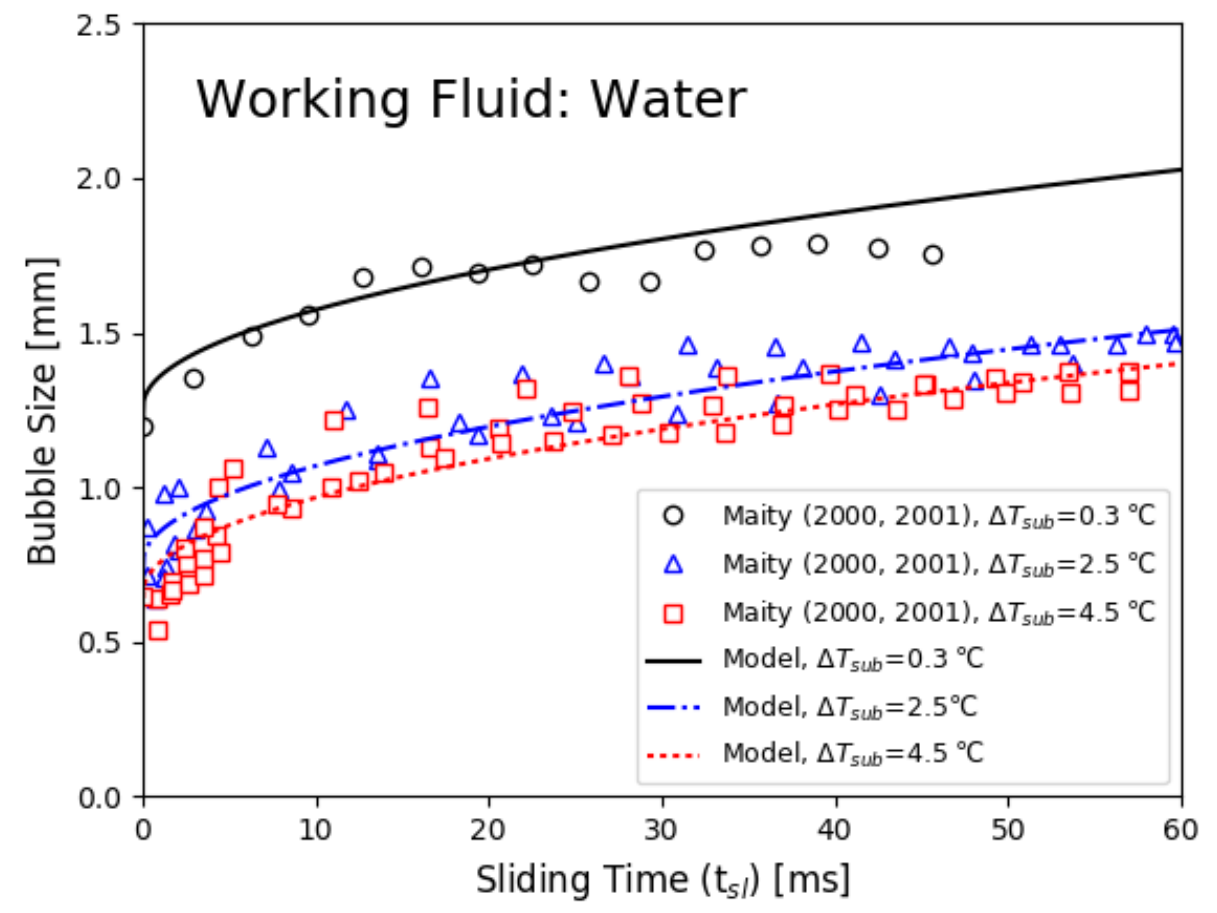

Fig. 4. Sliding bubble size prediction compared with Maity's data $(2000,2001)$ (Physical dependency on subcooling degree at a given mass flux $\mathrm{G}=240 \mathrm{~kg} / \mathrm{m}^{2}$ ).

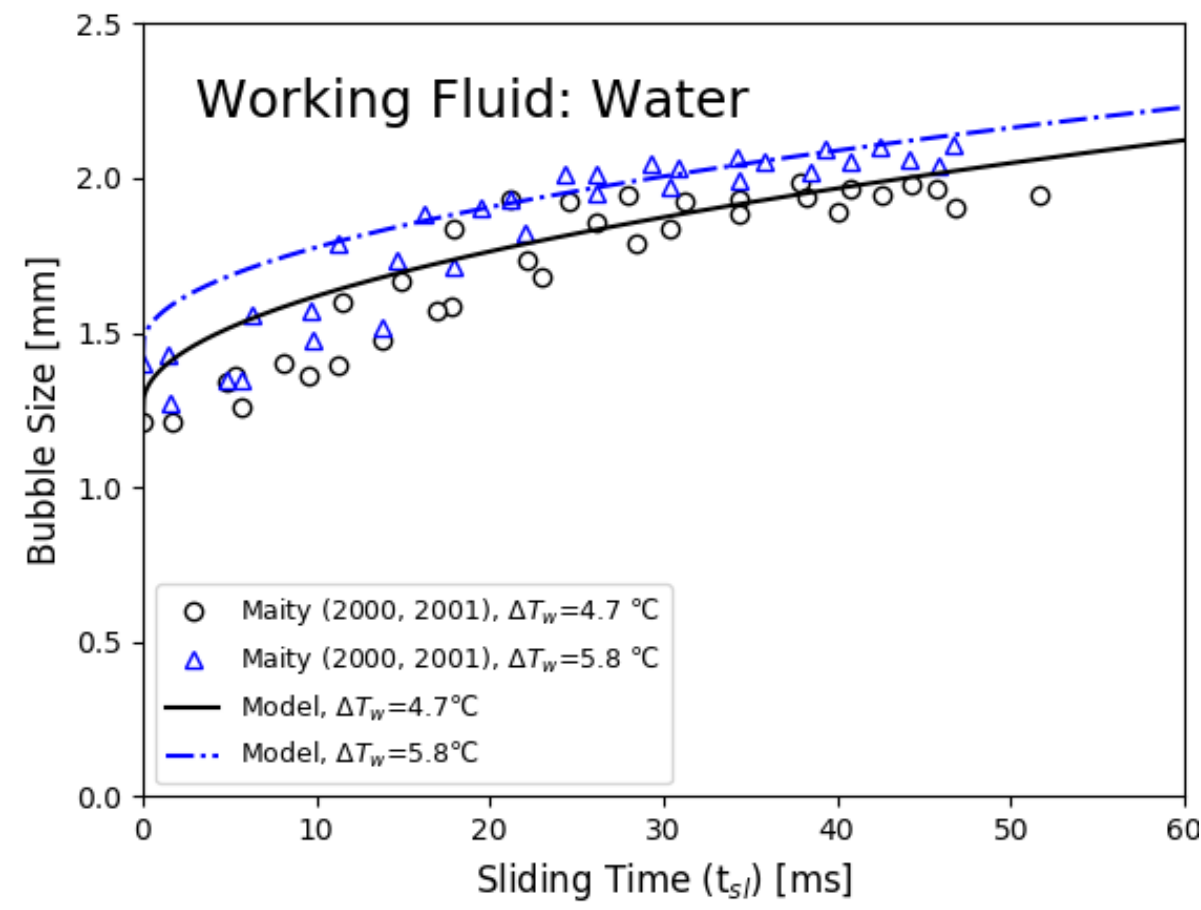

Fig. 5. Sliding bubble size prediction compared with Maity's data [9, 40] (Physical dependency on wall superheat at a given mass flux $\mathrm{G}=134 \mathrm{~kg} / \mathrm{m}^{2}$ ). 


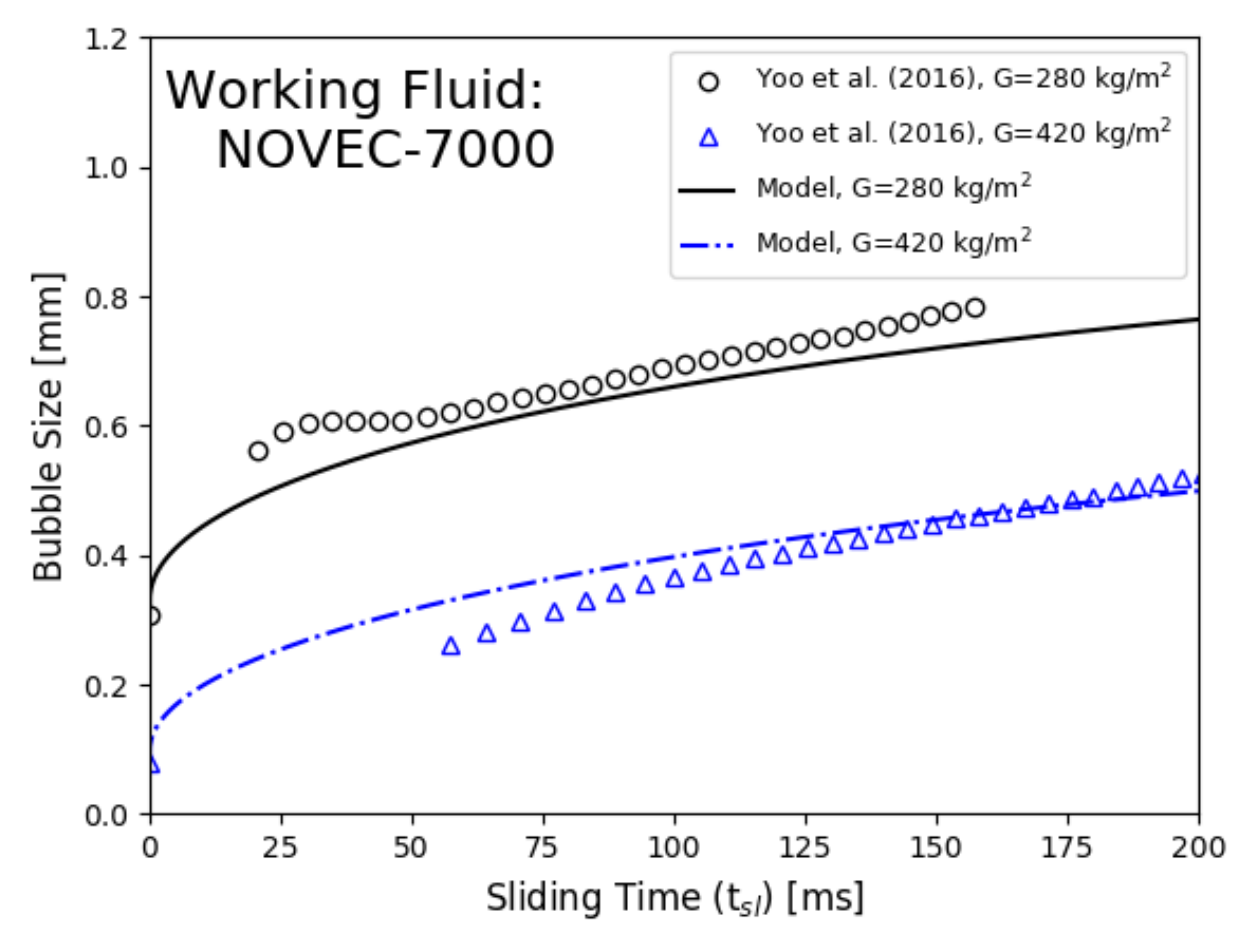

Fig. 6. Sliding bubble size prediction compared with Yoo et al.'s data [3] (Physical dependency on mass flux at a given wall heat flux $q_{w}{ }^{\prime \prime} \approx 12.0 \mathrm{~kW} / \mathrm{m}^{2}$ ).

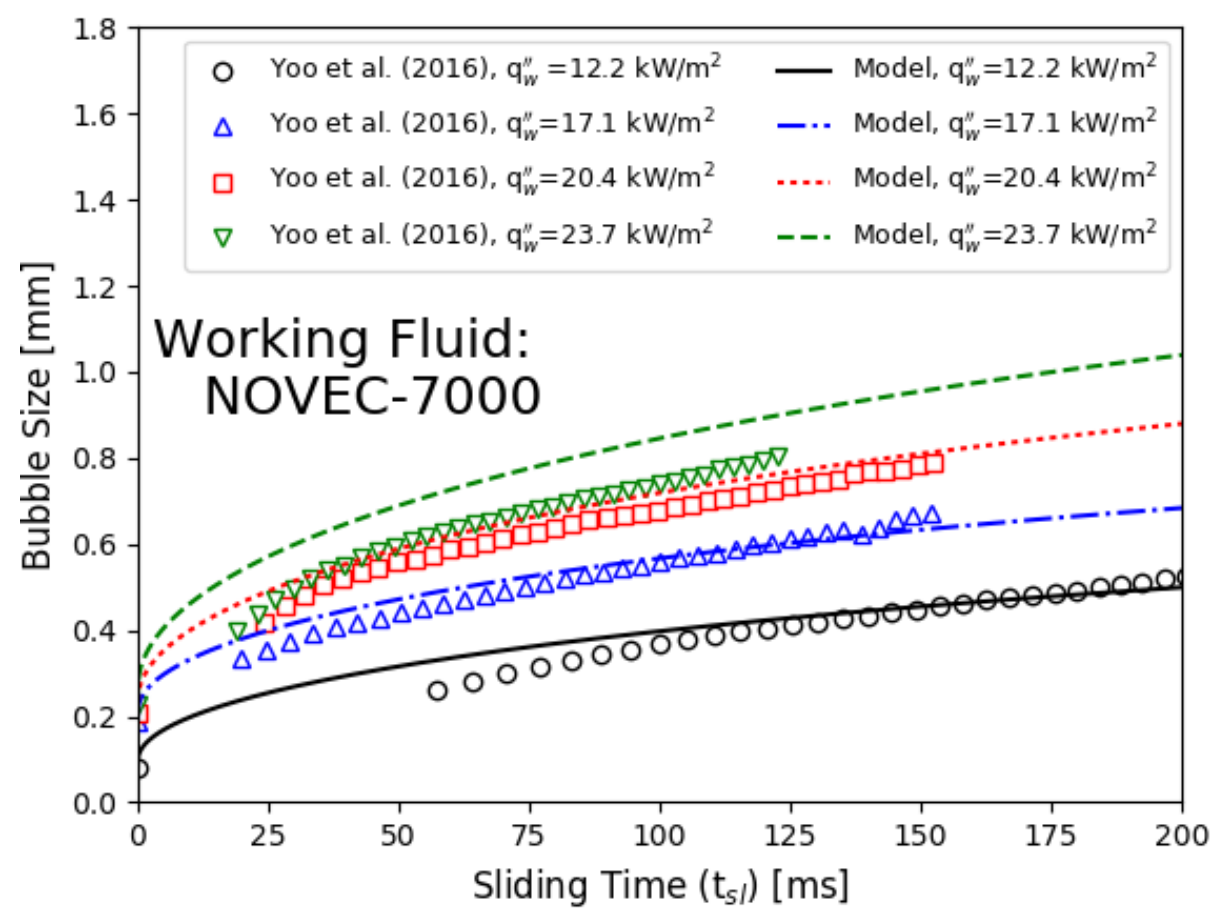

Fig. 7. Sliding bubble size prediction compared with Yoo et al.'s data [3] (Physical dependency on wall heat flux at a given mass flux $\mathrm{G}=420 \mathrm{~kg} / \mathrm{m}^{2}$ ). 


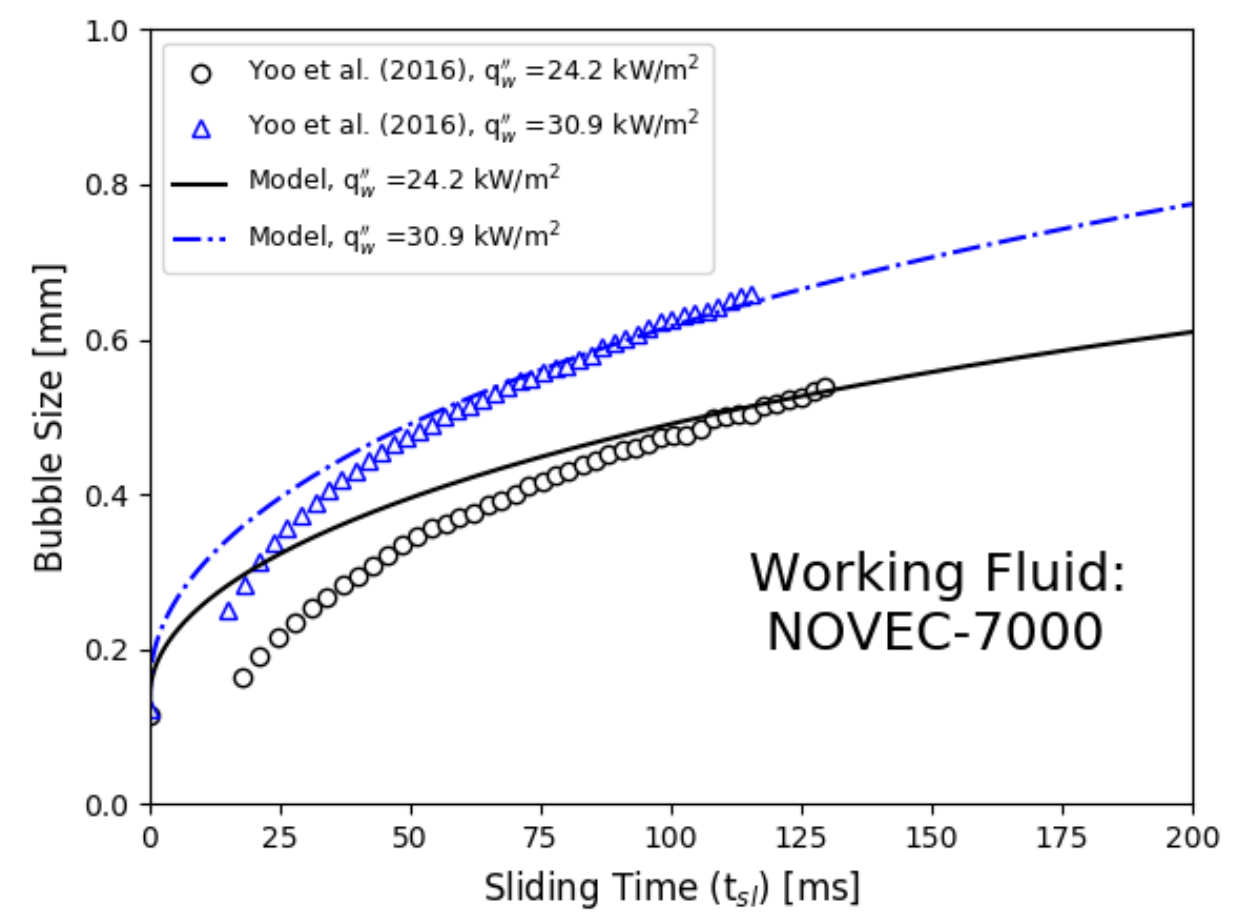

Fig. 8. Sliding bubble size prediction compared with Yoo et al.'s data [3] (Physical dependency on wall heat flux at a given mass flux $\mathrm{G}=700 \mathrm{~kg} / \mathrm{m}^{2}$ ).
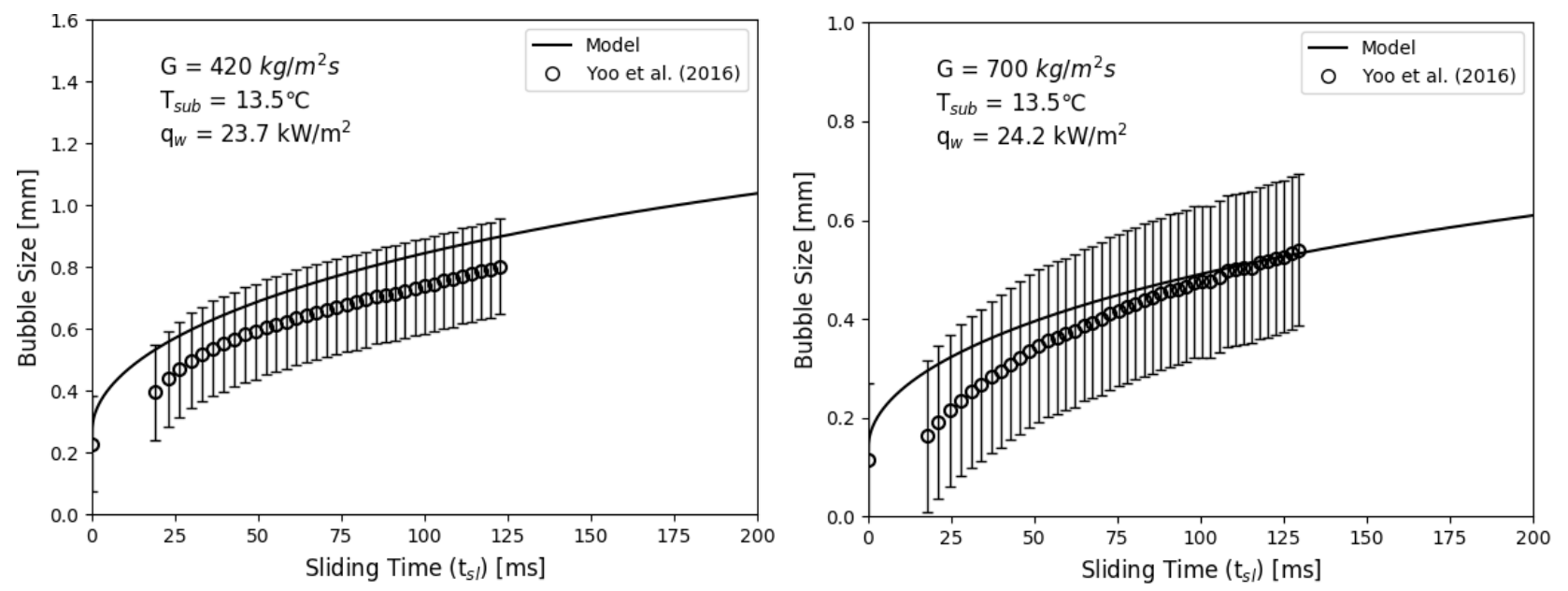

Fig. 9. Model prediction compared with Yoo et al.'s data [3] considering experimental uncertainty. 


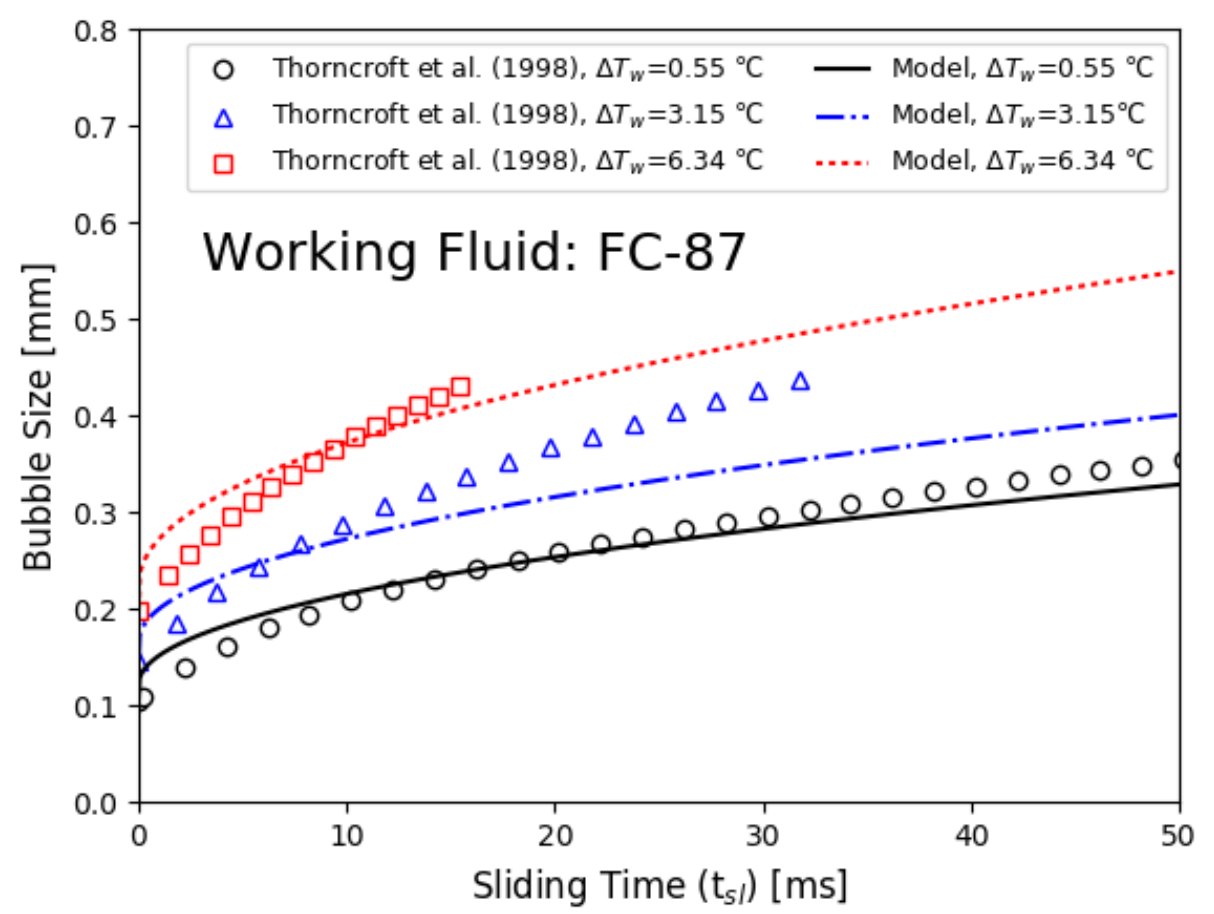

Fig. 10. Sliding bubble size prediction compared with Thorncroft et al.'s data [41] (Physical dependency on wall superheat at a given mass flux $\mathrm{G}=244-258 \mathrm{~kg} / \mathrm{m}^{2} \mathrm{~s}$ ).

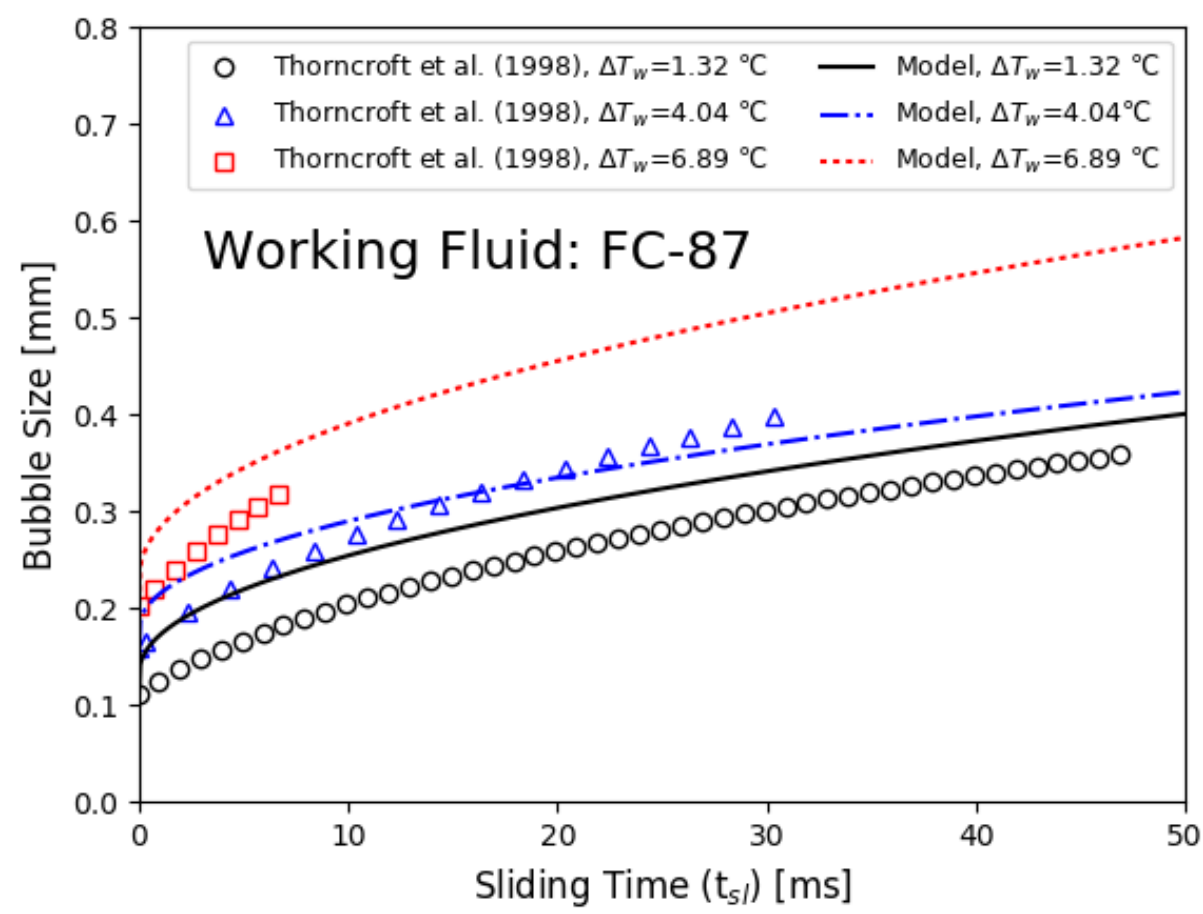

Fig. 11. Sliding bubble size prediction compared with Thorncroft et al.'s data [41] (Physical dependency on wall superheat at a given mass flux $\mathrm{G}=315-319 \mathrm{~kg} / \mathrm{m}^{2} \mathrm{~s}$ ). 


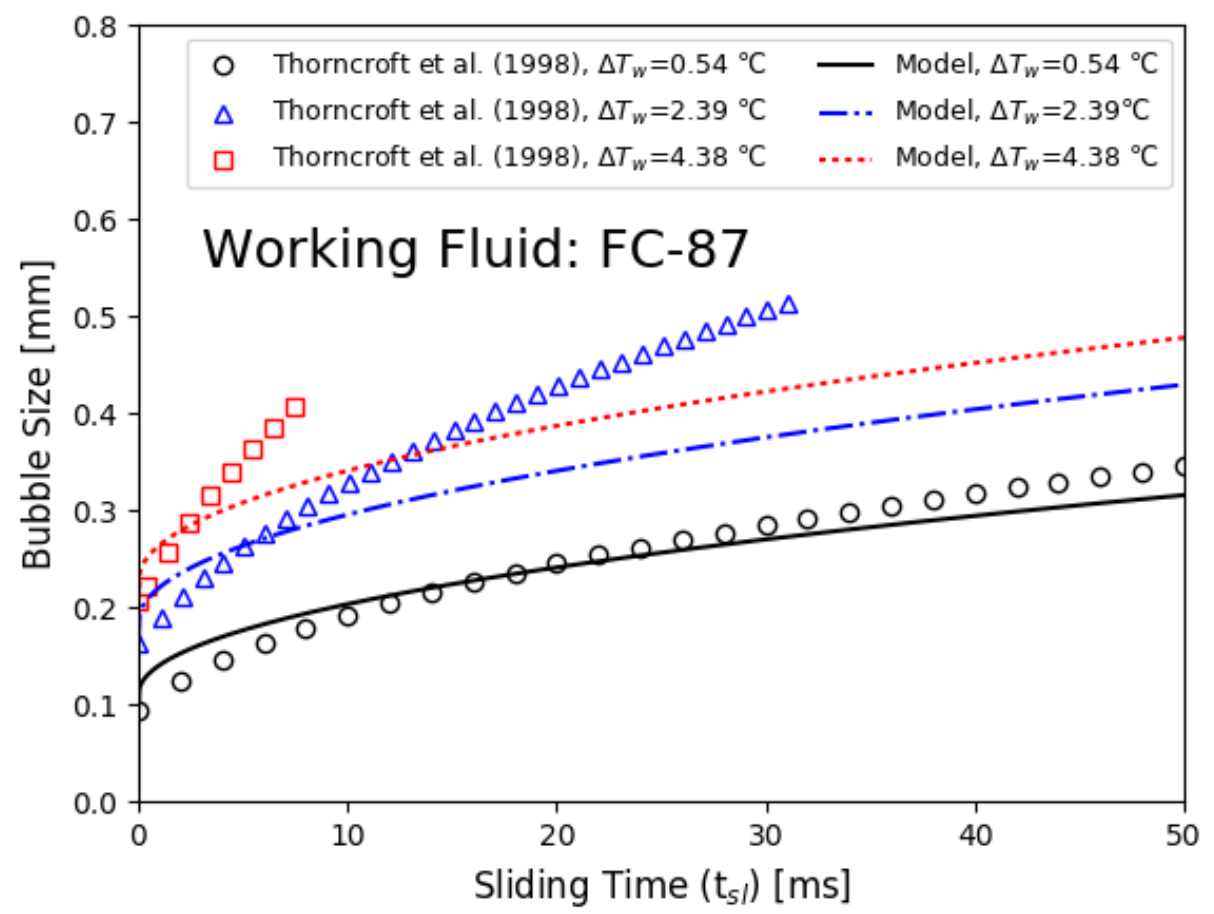

Fig. 12. Sliding bubble size prediction compared with Thorncroft et al.'s data [41] (Physical dependency on wall superheat at a given mass flux G=192-195 kg/m² $\mathrm{s}$ ). 

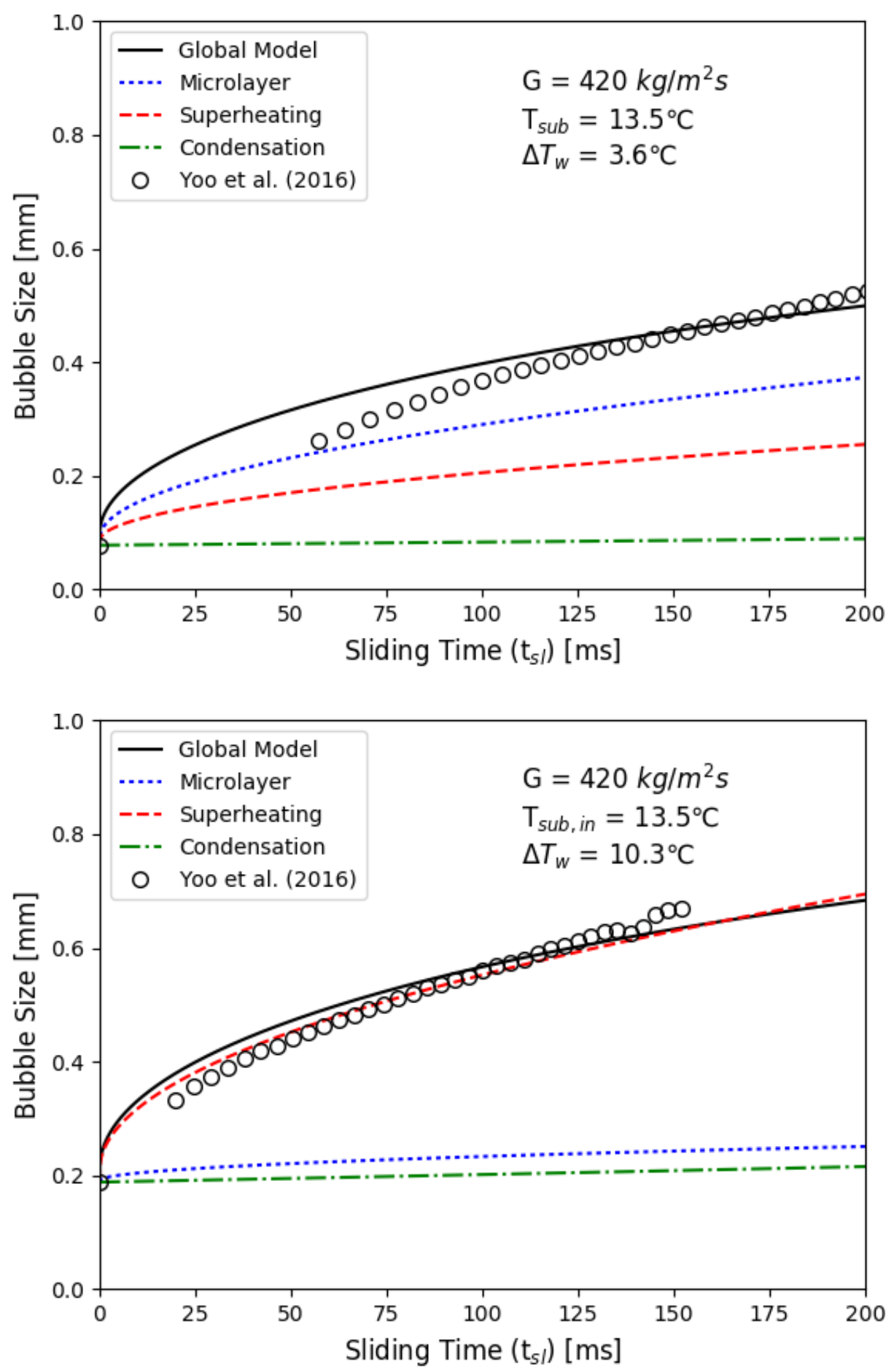

Fig. 13. Contribution of individual heat transfer components estimated at two different wall superheat conditions of Yoo et al. experiment [3]. 

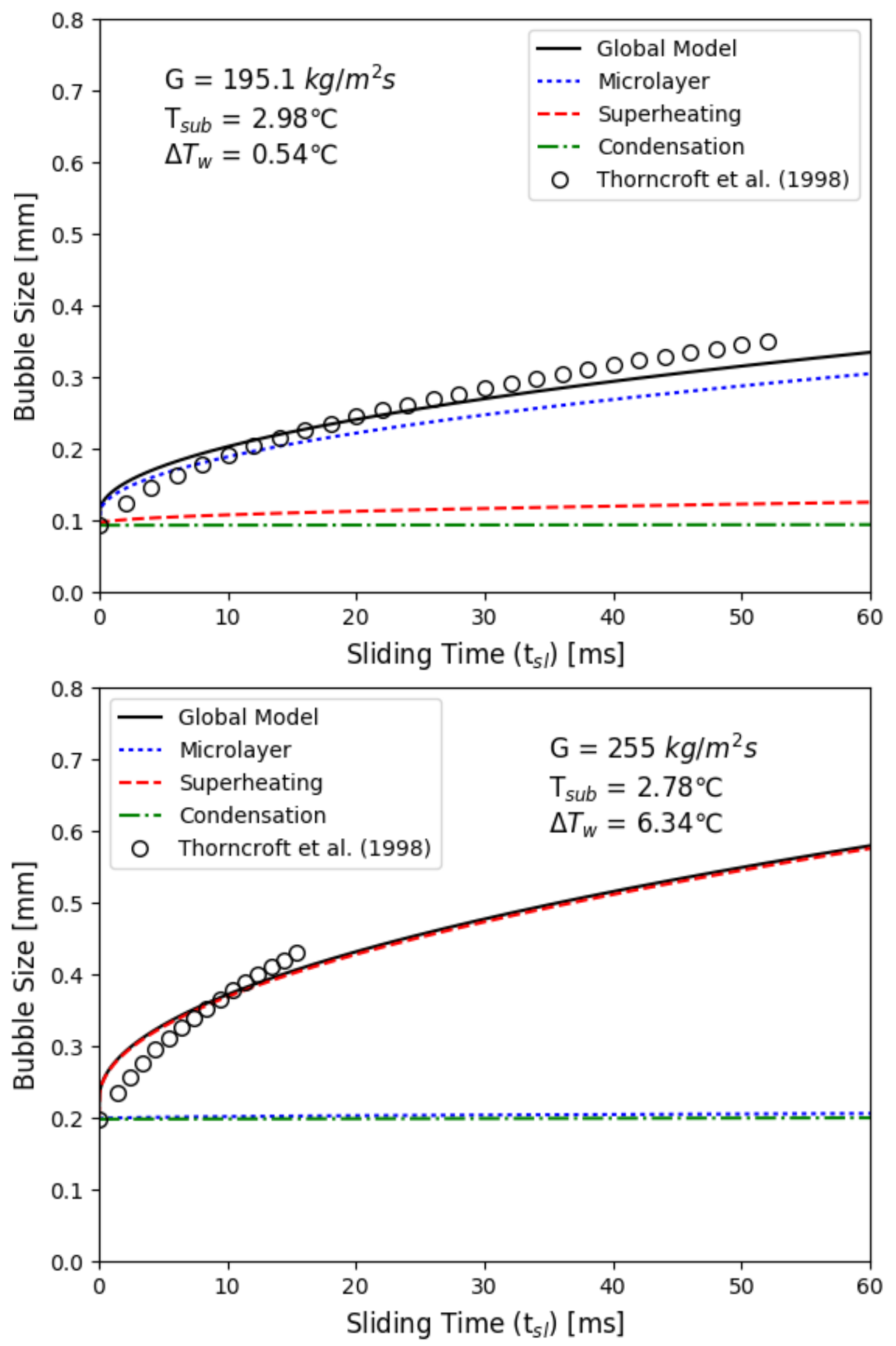

Fig. 14. Contribution of individual heat transfer components estimated at two different wall superheat conditions of Thorncroft et al. experiment [41]. 


\section{CONCLUSION}

A new mechanistic model for predicting the growth of sliding bubbles has been developed in this study. This model employs a physical base that the fundamental mechanisms applied to the bubble growth at a nucleation site can also be applied to the growth of sliding bubbles. The growth mechanisms taken into account in the present model are microlayer evaporation, superheated liquid evaporation, and condensation. Several physical assumptions and empirical constants used in the existing models have been modified to reflect the intrinsic physics associated with sliding bubble growth. One of the major modifications is that the area of the microlayer ( or $A_{m} / A_{\text {tot }}$ ) was determined based on the wall superheat and heater wall thermal properties. A new growth constant was also introduced to evaluate the contribution of the superheated liquid $\left(q_{S L L}\right)$. Lastly, to avoid the issue of overestimation of the condensation heat transfer in the existing models, modification was made based on Unal model [12].

The present model has been successfully validated against the experimental data for a wide range of subcooled flow boiling conditions, with the datasets generated by three separate research groups using different working fluids and heater surfaces. The physical dependency of bubble growth during sliding on the relevant flow boiling parameters (i.e., mass flux, wall superheat, and subcooling level) observed in these experiments was well reproduced by the model.

It is important to note that the growth behavior of sliding bubble can significantly affect the evaluation of other sliding bubble parameters. As discussed in our previous study [3,7], the bubble size during sliding has a critical impact on the wall area influenced by sliding bubbles and sliding velocity, or other parameters. Therefore, the accurate prediction of sliding bubble growth using the present model is an important starting point to improve the overall performance of the sliding bubble model package for the CFD boiling prediction. In addition, in view of evaluating the various forces around a bubble to mechanistically predict the bubble lift-off diameter, the present model would be become a useful piece of improvement for the force balance model [32]. 


\section{REFERENCES}

1. Cornwell, K., The influence of bubbly flow on boiling from a tube in a bundle. International Journal of Heat and Mass Transfer, 1990. 33(12): p. 2579-2584.

2. Houston, S. and K. Cornwell, Heat transfer to sliding bubbles on a tube under evaporating and non-evaporating conditions. International journal of heat and mass transfer, 1996. 39(1): p. 211214.

3. Yoo, J., C.E. Estrada-Perez, and Y.A. Hassan, Experimental study on bubble dynamics and wall heat transfer arising from a single nucleation site at subcooled flow boiling conditions-Part 2: Data analysis on sliding bubble characteristics and associated wall heat transfer. International Journal of Multiphase Flow, 2016. 84: p. 292-314.

4. Thorncroft, G. and J. Klausner, The influence of vapor bubble sliding on forced convection boiling heat transfer. ASME J. Heat Transfer, 1999. 121(1): p. 73-79.

5. Yeoh, G., et al., Fundamental consideration of wall heat partition of vertical subcooled boiling flows. International Journal of Heat and Mass Transfer, 2008. 51(15): p. 3840-3853.

6. Gilman, L. and E. Baglietto, A self-consistent, physics-based boiling heat transfer modeling framework for use in computational fluid dynamics. International Journal of Multiphase Flow, 2017. 95: p. 35-53.

7. Yoo, J., C.E. Estrada-Perez, and Y.A. Hassan, Wall area of influence and growing wall heat transfer due to sliding bubbles in subcooled boiling flow, in NUTHOS-11.2016: Gyeongju, Korea.

8. Basu, N., G.R. Warrier, and V.K. Dhir, Wall heat flux partitioning during subcooled flow boiling: Part 1-model development. Journal of heat Transfer, 2005. 127(2): p. 131-140.

9. Maity, S., Effect of velocity and gravity on bubble dynamics. 2000, UCLA.

10. Cooper, M. and A. Lloyd, The microlayer in nucleate pool boiling. International Journal of Heat and Mass Transfer, 1969. 12(8): p. 895-913.

11. Snyder, N. and T. Robin, Mass-transfer model in subcooled nucleate boiling. Journal of Heat Transfer, 1969. 91(3): p. 404-411.

12. Ünal, H., Maximum bubble diameter, maximum bubble-growth time and bubble-growth rate during the subcooled nucleate flow boiling of water up to $17.7 \mathrm{MN} / \mathrm{m} 2$. International Journal of Heat and Mass Transfer, 1976. 19(6): p. 643-649.

13. Zuber, N., The dynamics of vapor bubbles in nonuniform temperature fields. International Journal of Heat and Mass Transfer, 1961. 2(1-2): p. 83-98.

14. Hoang, N.H., et al., A mechanistic model for predicting the maximum diameter of vapor bubbles in a subcooled boiling flow. International Journal of Heat and Mass Transfer, 2016. 94: p. 174179.

15. Plesset, M. and S.A. Zwick, The growth of vapor bubbles in superheated liquids. Journal of Applied Physics, 1954. 25(4): p. 493-500.

16. Stephan, P. and J. Hammer, A new model for nucleate boiling heat transfer. Heat and Mass Transfer, 1994. 30(2): p. 119-125.

17. Van Stralen, S., et al., Bubble growth rates in pure and binary systems: combined effect of relaxation and evaporation microlayers. International Journal of Heat and Mass Transfer, 1975. 18(3): p. 453-467.

18. Zeng, L.Z., et al., A Unified Model for the Prediction of Bubble Detachment Diameters in Boiling Systems .2. Flow Boiling. International Journal of Heat and Mass Transfer, 1993. 36(9): p. 22712279.

19. Steiner, H., A. Kobor, and L. Gebhard, A wall heat transfer model for subcooled boiling flow. International Journal of Heat and Mass Transfer, 2005. 48(19-20): p. 4161-4173. 
20. Cho, Y.-J., et al., Development of bubble departure and lift-off diameter models in low heat flux and low flow velocity conditions. International Journal of Heat and Mass Transfer, 2011. 54(15): p. 3234-3244.

21. Scriven, L., On the dynamics of phase growth. Chemical engineering science, 1959. 10(1-2): p. 113.

22. Yun, B.-J., et al., Prediction of a subcooled boiling flow with advanced two-phase flow models. Nuclear engineering and design, 2012. 253: p. 351-359.

23. Ranz, W. and W. Marshall, Evaporation from drops. Chem. Eng. Prog, 1952. 48(3): p. 141-146.

24. Levenspiel, O., Collapse of steam bubbles in water. Industrial \& Engineering Chemistry, 1959. 51(6): p. 787-790.

25. Colombo, M. and M. Fairweather, Prediction of bubble departure in forced convection boiling: A mechanistic model. International Journal of Heat and Mass Transfer, 2015. 85: p. 135-146.

26. Raj, S., M. Pathak, and M.K. Khan, An analytical model for predicting growth rate and departure diameter of a bubble in subcooled flow boiling. International Journal of Heat and Mass Transfer, 2017. 109: p. 470-481.

27. Kader, B., Temperature and concentration profiles in fully turbulent boundary layers. International journal of heat and mass transfer, 1981. 24(9): p. 1541-1544.

28. Sugrue, R. and J. Buongiorno, A modified force-balance model for prediction of bubble departure diameter in subcooled flow boiling. Nuclear Engineering and Design, 2016. 305: p. 717-722.

29. Kim, J., Review of nucleate pool boiling bubble heat transfer mechanisms. International Journal of Multiphase Flow, 2009. 35(12): p. 1067-1076.

30. Bankoff, S. and J. Mason, Heat transfer from the surface of a steam bubble in turbulent subcooled liquid stream. AIChE Journal, 1962. 8(1): p. 30-33.

31. Yoo, J., C.E. Estrada-Perez, and Y.A. Hassan, Experimental study on bubble dynamics and wall heat transfer arising from a single nucleation site at subcooled flow boiling conditions-Part 1: Experimental methods and data quality verification. International Journal of Multiphase Flow, 2016. 84: p. 315-324.

32. Klausner, J., et al., Vapor bubble departure in forced convection boiling. International journal of heat and mass transfer, 1993. 36(3): p. 651-662.

33. Zeng, L.Z., J.F. Klausner, and R. Mei, A Unified Model for the Prediction of Bubble Detachment Diameters in Boiling Systems .1. Pool Boiling. International Journal of Heat and Mass Transfer, 1993. 36(9): p. 2261-2270.

34. Kim, S.-J. and G.-C. Park, Interfacial heat transfer of condensing bubble in subcooled boiling flow at low pressure. International Journal of Heat and Mass Transfer, 2011. 54(13): p. 29622974.

35. Warrier, G.R., N. Basu, and V.K. Dhir, Interfacial heat transfer during subcooled flow boiling. International Journal of Heat and Mass Transfer, 2002. 45(19): p. 3947-3959.

36. Chen, Y. and F. Mayinger, Measurement of heat transfer at the phase interface of condensing bubbles. International journal of multiphase flow, 1992. 18(6): p. 877-890.

37. Zeitoun, O., M. Shoukri, and V. Chatoorgoon, Measurement of Interfacial Area Concentration in Subcooled Liquid-Vapor Flow. Nuclear Engineering and Design, 1994. 152(1-3): p. 243-255.

38. Demiray, F. and J. Kim, Microscale heat transfer measurements during pool boiling of FC-72: effect of subcooling. International Journal of Heat and Mass Transfer, 2004. 47(14): p. 32573268.

39. Utaka, Y., et al., Heat transfer characteristics based on microlayer structure in nucleate pool boiling for water and ethanol. International Journal of Heat and Mass Transfer, 2014. 68: p. 479488.

40. Maity, S. and V. Dhir. An experimental study of vapor bubble dynamics on inclined surfaces subjected to forced flow along the surface. in Proceedings of 35th National Heat Transfer Conference, Anaheim, CA, USA. 2001. 
41. Thorncroft, G., J. Klausnera, and R. Mei, An experimental investigation of bubble growth and detachment in vertical upflow and downflow boiling. International Journal of Heat and Mass Transfer, 1998. 41(23): p. 3857-3871.

42. Yoo, J., C.E. Estrada-Perez, and Y.A. Hassan, A proper observation and characterization of wall nucleation phenomena in a forced convective boiling system. International Journal of Heat and Mass Transfer, 2014. 76: p. 568-584. 